\title{
Business Intelligence \& Analytics Cost Accounting: A Survey on the Perceptions of Stakeholders
}

\author{
Raphael Grytz \\ Paderborn University \\ grytz@aisbi.de
}

\author{
Artus Krohn-Grimberghe \\ Paderborn University \\ artus@aisbi.de
}

\begin{abstract}
As data driven decision-making using business intelligence and analytics (BI\&A) becomes standard in companies, the importance of mitigating the accompanying growth in costs increases. Research shows that increasing transparency to the granularity of individual BI\&A artefacts such as reports or analytic applications is a necessary means, but in practice the introduction of said systems is cumbersome and adoption is slow. We address the status quo of BI\&A cost accounting for three types of stakeholders: users, developers and managers. The results show in which areas of application a strong need for action exists and we identify major challenges for further research are ahead. Our findings indicate for example that managers at the same time regard cost accounting for BI\&A with a higher potential benefit while they also believe they have already established a higher degree of implementation in their enterprises compared to the other stakeholder types. We conclude that BI\&A professionals have to consider these different perceptions to run a successful department and gain traction for BI\&A cost accounting.
\end{abstract}

\section{Introduction}

To compete successfully in the marketplace, it is becoming increasingly important for an enterprise to utilize the full potential of data-driven decision support that Business Intelligence \& Analytics (BI\&A) promises [24]. Chen et al. [5] define BI\&A as "the techniques, technologies, systems, practices, methodologies, and applications that analyze critical Business data to help an enterprise better understand its business and market and make the timely decisions it needs". In most enterprises, an internal department for BI\&A, which in most cases is organized as a BI Competency Center (BICC) [23], provides this information through a company-specific BI\&A architecture and organization. Today, the benefits of
BI\&A are undisputed and it has reached most enterprises.

While current discussions in the field of BI\&A are dominated by potential benefits of big data $[1,19]$, the costs of establishing and maintaining BI\&A systems are often overlooked. Due to complex architectures [17], in addition to the high speed of innovation in technology and methods [5], the costs of BI\&A have recently increased. The costs associated with such systems need to be transparent to management to allow for correct business decision-making [24]. This is especially important during times of increased global competition [12, 22].

We believe, this lack of cost transparency is a significant driver for increasing BI\&A costs. If customers are not paying for BI\&A resources, then they have no interest in saving money for the company. To increase consciousness, customers have to pay the cost for services they demand. Payment must then be charged without this billing disproportionate costs. Besides being cheap and efficient, such an accounting system is fair inasmuch as service consumers have to pay for the costs they cause [14]. Additionally, without such a system, outlay cannot be priced reliably; this is true for the company's entire BI\&A investments as well as individual applications within the BI\&A department. Although companies are looking for new outsourcing opportunities, e.g. delivering BI\&A as a service [2, 15], without cost transparency any outsourcing decisions with respect to specific parts of a BI\&A landscape cannot be evaluated. Furthermore, it is difficult to locate potential for improving efficiency and productivity, for planning the use of resources, and for justifying it to management. With improved cost transparency, a BI\&A department can locate cost savings and cost drivers.

The necessary cost transparency can be provided by a BI\&A cost accounting system. Such a system can be used as a managerial instrument which delivers information about value streams and for planning, controlling and monitoring all tasks in the BI\&A organization $[16,20]$ in a fast, efficient, and data- 
driven way. Current research on BI\&A cost accounting regarding management objectives and design principles [10] shows the importance of this topic on a managerial level as well as first realistic implementation guidelines [14].

With an appropriate cost accounting system, it will also become possible to calculate costs for both individual $\mathrm{BI} \& \mathrm{~A}$ artefacts and entire $\mathrm{BI} \& \mathrm{~A}$ projects. In addition, with the ability to calculate BI\&A applications, incoming BI\&A demands could be prioritized according to their expected benefit (value). This would improve the efficiency (cost-benefit perspective) of the whole BI\&A department and increase the productivity of BI\&A resources. Aside from the possibility of allowing make-or-buy decisions or cost benchmarks to be made, improved cost transparency would come one step closer to performing a profitability analysis.

Even with the recent proposals, especially the one from [14] becoming more feasible both from an implementation and a consumption view, the introduction of a BI\&A related cost accounting in the enterprise often fails or is not seen to be successful. One of the reasons for less success in practice could be the divergent perceptions of stakeholders regarding information systems (IS) [28]. In particular, this is true of the success of analytic information systems where the perception of different stakeholders is identified as a significant characteristic [27]. Yet there is not sufficient study of whether, and to what extent, the perceptions of stakeholders related to BI\&A cost accounting reveal differences regarding and negative influence on the introduction of such a system. Therefore, the core question of this paper is this: Are there different perceptions of stakeholders affected which could influence the success of a cost accounting initiative for BI\&A and, if so, how can these divergent perceptions be identified? To close this research gap, we carry out a descriptive-explorative survey in order to collect required data and permit further analysis. More precisely, we aim to examine the issue by developing sensitivity for the different subjective assessments of the potential benefits, the degree of implementation, and the implementation challenges regarding a BI\&A cost accounting. We see our results being used to assist BI\&A professionals planning to introduce cost accounting approaches for BI\&A in companies.

Our main contributions are:

- Divergent perceptions among users, developers, and managers. Our findings confirm that there are indeed substantial differences in the perception of BI\&A cost accounting and the implementation of such systems among the three major stakeholder groups (users, developers, managers) included in the survey.

- Identification of the differences in perception for single stakeholder groups. We note that stakeholders have different priorities and potentials regarding a BI\&A cost accounting system. For example users assessed the potential benefit for continuous cancellation management by cost evaluation as low. By contrast, developers predict less potential benefit from outsourcing opportunities, whereas managers assessed the highest potential benefit for justification towards management. If these different perceptions are not considered during the planning process, the introduction of the BI\&A cost accounting system is endangered.

- Selling the BI\&A cost accounting to the enterprise. The differences we found among the stakeholder groups stipulate that selling the idea of BI\&A cost accounting works best when building on the intrinsic motivation of the managers while leveraging the more positive attitude of the developers and users.

- Higher acceptance of BI\&A cost accounting and project success. We offer a definition and way of prioritizing the needs for action and challenges resulting from the implementation of a BI\&A cost accounting system. Proper prioritization aligned with user needs helps increase acceptance and thus project success.

- High potential among all stakeholder groups. Last but not least, we can confirm that all stakeholder groups see a high potential in the establishment of a BI\&A cost accounting system. This also highlights the necessity of action to implement a BI\&A cost accounting system in order to improve the cost transparency in BI\&A departments among the organizations surveyed.

With this research, we contribute to implementing cost accounting for BI\&A in companies and create a foundation for further research to this topic.

The rest of this paper is organized as follows. Section 2 describes the conceptual foundations for this paper. In chapter 2.1, we present the current research on BI\&A cost accounting. The influence of the stakeholder perspective on IS in general and BI\&A in particular will be dealt with in Section 2.2. Our research concept is described in Section 3, above all the research method used and a statistical description of our sample. Section 4 holds the presentation of our analysis and discussion of findings. The last section concludes with an explanation of the limitations and gives an outlook on future work. 


\section{Conceptual foundation}

In this section, we give a brief overview of the current research on BI\&A cost accounting. Furthermore, we present relevant knowledge about the influence of stakeholder perspectives on IS and BI\&A success.

\subsection{A brief overview of the current research on BI\&A cost accounting}

At present, increasing demands for BI\&A continue to challenge existing BI\&A landscapes in companies. From IS literature, it is clear that architectures, organizations, and technologies must be adapted [19]; this, however, often results in an increase in costs. In our experience, BI\&A departments are under rising cost pressure and must demonstrate efficiency, productivity, and cost optimization on a day-by-day basis. Consequently, these departments are forced to try and justify a monolithic BI\&A cost block to management. Cost allocation systems to mitigate this problem are identified in the literature $[11,18,26]$. However, usually few details are given: there are some frameworks for summing up the total cost of BI\&A technology landscapes in companies e. g. by return on investment (ROI) level [22, 30]; there are also some other approaches proposing cost estimation based on resource consumption $[4,21]$. The paper by Brandl et al. [4] introduces a method aimed at determining usage-based cost allocation keys for customeroriented services based on their estimated resource consumption. This can be achieved if every user request is tracked across systems using a unique user ID, resulting in detailed monitoring and metering of users' resource consumption. This approach only deals about allocation keys without proposing a whole cost accounting related to BI\&A. Klesse [21] focuses on a method of carrying out cost allocation for data warehouse competency centers (DWH CC). Products and services of the DWH CC are modeled as so-called information products; for a modeled information product, platform and process services must be assigned in detail. Due to the fact that the resulting cost accounting system is based on the information product model, accounting can be carried out in a very detailed fashion on the costs-by-cause principle, yet only for the DWH layer.

What is missing is a detailed holistic BI\&A cost accounting approach. Seeing it from an IT perspective, $[3,29]$ point out that IT costs allocation is necessary to improve cost transparency and that this is a challenging task with problems which remain unresolved; this holds true for BI\&A especially [14].
We concluded that, in literature to date, four principle kinds of cost accounting for BI\&A have been discussed: 1. No allocation of costs is executed. 2. Costs are allocated using flat-rate distribution keys. 3 . Costs are charged using a production-oriented allocation base, e. g. CPU or memory utilization. 4. Costs are calculated using product-oriented approaches which are too technical and overly detailed in their current form. Although BI\&A is driven by IT $[2,5,25]$, due to fundamental characteristics we discussed in [14], such as developmental and operational architecture, business domain, technical and functional requirements, costs which appear for BI\&A must be treated differently when thinking about a cost accounting. This makes it difficult to transfer and apply existing cost accounting approaches to BI\&A.

Grytz and Krohn-Grimberghe created a BI\&A service-oriented cost allocation (BIASOCA) [14] which quantifies and subsequently breaks down the cost pool generated by BI\&A in an understandable and yet efficient way. BI\&A services are defined through the activities carried out by a BI\&A department. The definition of an accounting net and a cost model then is used in combination with the mentioned BI\&A services to create a company-specific and understandable service catalog. This work improves cost transparency and enables internal processes for invoicing BI\&A service purchasers and consumers within the organization in a fairer and more exact way.

\subsection{Influence of the stakeholder perspective on IS evaluation}

There is no shortage of research on IS evaluation which both forms the basis of varied academic activity and is widely used in practice until today [6]. Early research emphasizes the existence of differences regarding the perspective from which the success or efficiency of IS is evaluated within organizations [28]. Often, these perspectives are classified by stakeholder types. Common types are end user (consumer), IT personnel, management, and external stakeholders [13]. The research on IS evaluation is also applied to BI\&A when it comes to success models where there is, as a minimum, differentiation by end-user-side and BI\&A department-side [7, 27]. However, in literature to date, there is a common understanding of how strongly the different stakeholder perspectives influence IS evaluation [28]. Referring to our research question in Section 1, the extant research on IS evaluation suggests that different stakeholder types in companies come to different assessments regarding BI\&A cost accounting initiatives. 


\section{Research concept}

The aim of this paper is to determine a way of producing practice-based estimates on the potential benefits and the degree of implementation for specific application areas of cost accounting for BI\&A. Beyond this, this study focuses on the current challenges for practical implementation of cost accounting for BI\&A. With the results of this paper, we are able to show need for action and identify barriers to new and further development of cost accounting for BI\&A. The next two subsections sum up the research method used and detail the demographic structure of our sample.

\subsection{Research method}

The underlying data used for this study was collected by a quantitative-empirical survey using a standardized online questionnaire. This survey includes all items which are used to answer our research question. The survey structure is based on investigations carried out by Dinter et al. [8]. The questionnaire consists of three parts: a general section about the respondent and the organization with their BI\&A environment, general questions about BI\&Arelated cost accounting, and a part regarding challenges and the use of BI\&A cost accounting. The survey items were readjusted so that they fit to the underlying topic of BI\&A cost accounting.

A short introduction to the term BI\&A cost accounting was given to ensure a common understanding. Consultants or academics were then asked to respond from the point of view of the customer they know best. Prior work by Dinter et al. [8] suggests to consider the BI life cycle of [9], for structuring the questions related to investigated application areas into BI\&A development/ operation, BI usage, and an organizational dimension. Table 1 gives an overview of the structure with investigated application areas. These application areas were assessed by a five-point Likert scale. The respondents were asked to assess the potential benefits (5="essential", $4=$ "high benefit", $3=$ ="nice to have", $2=$ "low benefit", $1=$ "no benefit") and the degree of implementation (5="implemented", 4="implementing", $\quad 3=$ "planned", $\quad 2=$ "initiative failed", 1="no entry") of the mentioned application areas.
Table 1. Application areas of BI\&A cost

\section{accounting}

BI\&A development/ operation

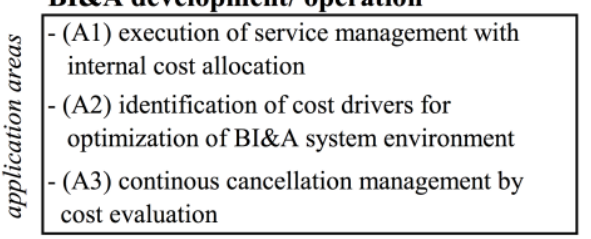

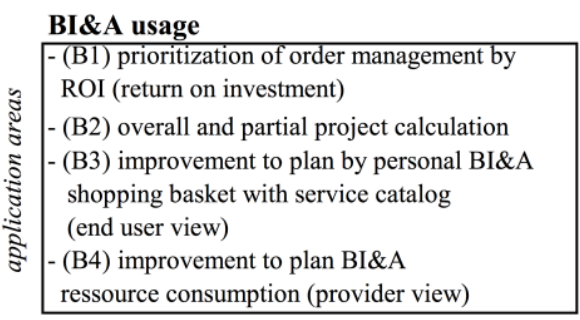

\begin{tabular}{|c|}
\hline Organizational application areas \\
\hline $\begin{array}{l}\text { - (C1) sensitization of customers for an } \\
\text { economical usage of BI\&A ressources } \\
\text { - (C2) increase of BI\&A acceptance by } \\
\text { improved cost understanding } \\
\text { - (C3) justification towards management } \\
\text { - (C4) allow make-or-buy decisions } \\
\text { - (C5) allow outsourcing comparisons } \\
\text { - (C6) allow cost benchmarking }\end{array}$ \\
\hline
\end{tabular}

Another perspective we intend to examine are the implementation challenges of BI\&A cost accounting. Table 2 gives an overview of the relevant items. The respondents also rate the efforts for this challenges on a five-point scale (1="insignificant", 2="low", 3="moderate", 4="huge", 5="insurmountable").

Table 2. Implementation challenges of BI\&A cost accounting

BI\&A implementation challenges

\begin{tabular}{l} 
- (D1) point up a business case \\
- (D2) winning a project sponsor \\
- (D3) convincing business users of potential \\
benefits \\
- (D4) availability of development resources \\
- (D5) availability of appropriate cost \\
accounting tools \\
- (D6) organizational establishment of cost \\
accounting \\
- (D7) technical integration of cost \\
accounting \\
- (D8) availability of appropriate cost \\
accounting approaches/ models for BI\&A \\
\hline
\end{tabular}

The questionnaire developed was evaluated by experts from industry and university on content, structure, and language. After this pre-test, feedback was considered and the structure was redesigned for better readability. The online questionnaire was sent at 
first to 1,202 German TDWI members (The Data Warehousing Institute) at the end of 2016. Additionally, this survey was posted in groups for business intelligence on XING.com. To gain a better result from practice, $\mathrm{BI} \& \mathrm{~A}$ departments from five large companies where asked to participate in the survey. After two months, this procedure was repeated. The online survey platform was configured so that each attendee could only participate once.

\subsection{Structure of the sample}

As we were focussing on BI\&A cost accounting, our target group were BI\&A stakeholders. We estimate that there was a total of about 3000 recipients for this survey; precisely 251 BI\&A stakeholders took part. Given this approximation of our potential attendees, we can assume a response rate of about $11.9 \%$. From this percentage, we collected 59 complete answer records. Table 3 presents an overview of our sample by company size and BI\&A experience.

To answer our research question, we considered the following three stakeholder types: BI\&A user, BI\&A developer, and BI\&A manager. External stakeholders are not included in this survey because we are looking at the internal structure of BI\&A organizations. Table 3 shows our sample divided by the three different stakeholder roles into BI\&A users with 21 participants $(35.6 \%)$, BI\&A developers with 24 participants $(40.7 \%)$, and BI\&A managers with 14 participants $(23.7 \%)$. We can classify our population as experienced, with $61.0 \%$ having "6 to 10 years" behind them in the area. BI\&A users above all classified themselves as less experienced, with up to 5 years $(23.7 \%)$.

In terms of the BI\&A organization, $49.2 \%$ deal with 100 to 999 BI\&A users. $25.4 \%$ of the participants are in companies with 1,000 and above 9,999 BI\&A users. Another interesting point is the heterogeneity of the BI\&A landscape: $44.1 \%$ are working with 3 up to 5 BI\&A vendors. $18.6 \%$ are served by one sole vendor and $15.3 \%$ use two. This corresponds to $47.5 \%$ of BI\&A organizations employing a "best of breed" approach; another $40.7 \%$ prefer to work with one single BI\&A suite.

Looking at the company size, the majority of the respondents are working in large companies with more than 1,000 employees $(83.0 \%)$; the remaining part work in medium-sized companies. $50.9 \%$ of these companies are in the production industry; the next greater part are IT software companies (10.2\%). Another $38.9 \%$ is more or less spread over other categories of companies, with bank and financial service providers $(6.8 \%)$ and energy supply/ trading $(5.1 \%)$ as the largest groups.

Our survey points out that BI\&A cost accounting is important $(47.3 \%)$ and indispensable for $11.9 \%$ of the participants (cp. Table 4). Another $25.5 \%$ rated BI\&A cost accounting as "nice to have". Beside this, more than the half of our population $(54.2 \%)$ have no form of cost accounting in their BI\&A organization. $28.8 \%$ are using a product-oriented allocation whereas $3.4 \%$ allocate their costs over a production-oriented allocation. But another aspect shows that $23.7 \%$ of the participants are planning or are currently in an implementation stage of their cost accounting initiative.

Table 3. Overview of sample structure

\begin{tabular}{|c|c|c|c|c|c|c|c|}
\cline { 3 - 7 } \multicolumn{1}{c|}{} & \multicolumn{4}{c|}{ Company size } & \multicolumn{4}{c|}{ BI\&A Experience } & \multicolumn{1}{c|}{$\begin{array}{c}\text { Types of } \\
\text { stakeholder }\end{array}$} & Up to 1,000 & $1,000-4,999$ & $>5,000$ & Up to 5 years & $6-10$ years & > 10 years & Total \\
\hline BI\&A user & 4 & 11 & 6 & 14 & 3 & 4 & 21 \\
& $(6.8 \%)$ & $(18.6 \%)$ & $(10.2 \%)$ & $(23.7 \%)$ & $(5.1 \%)$ & $(6.8 \%)$ & $(35.6 \%)$ \\
\hline BI\&A developer & 3 & 17 & 4 & 6 & 11 & 7 & 24 \\
& $(5.1 \%)$ & $(28.8 \%)$ & $(6.8 \%)$ & $(10.2 \%)$ & $(18.6 \%)$ & $(11.9 \%)$ & $(40.7 \%)$ \\
\hline BI\&A manager & 3 & 6 & 5 & 3 & 4 & 7 & 14 \\
& $(5.1 \%)$ & $(10.2 \%)$ & $(8.5 \%)$ & $(5.1 \%)$ & $(6.8 \%)$ & $(11.9 \%)$ & $(23.7 \%)$ \\
\hline \hline & 10 & 34 & 15 & 23 & 18 & 18 & 59 \\
Total & $(16.9 \%)$ & $(57.6 \%)$ & $(25.4 \%)$ & $(39.0 \%)$ & $(30.5 \%)$ & $(30.5 \%)$ & $(100 \%)$ \\
\hline
\end{tabular}

Table 4. Importance of BI\&A cost accounting

\begin{tabular}{|c|c|c|c|c|c|c|}
\hline \multirow[b]{2}{*}{$\begin{array}{c}\text { Types of } \\
\text { stakeholder }\end{array}$} & \multicolumn{5}{|c|}{ Importance of BI\&A cost accounting } & \multirow[b]{2}{*}{ Total } \\
\hline & Indispensable & Important & Nice to have & Less important & Superfluous & \\
\hline BI\&A user & $\begin{array}{c}2 \\
(3.4 \%)\end{array}$ & $\begin{array}{c}7 \\
(11.8 \%)\end{array}$ & $\begin{array}{c}6 \\
(10.2 \%)\end{array}$ & $\begin{array}{c}4 \\
(6.8 \%)\end{array}$ & $\begin{array}{c}2 \\
(3.4 \%)\end{array}$ & $\begin{array}{c}21 \\
(35.6 \%)\end{array}$ \\
\hline BI\&A developer & $\begin{array}{c}2 \\
(3.4 \%)\end{array}$ & $\begin{array}{c}13 \\
(22.0 \%)\end{array}$ & $\begin{array}{c}7 \\
(11.9 \%)\end{array}$ & $\begin{array}{c}1 \\
(1.7 \%)\end{array}$ & $\begin{array}{c}1 \\
(1.7 \%)\end{array}$ & $\begin{array}{c}24 \\
(40.7 \%)\end{array}$ \\
\hline BI\&A manager & $\begin{array}{c}3 \\
(5.1 \%)\end{array}$ & $\begin{array}{c}8 \\
(13.5 \%)\end{array}$ & $\begin{array}{c}2 \\
(3.4 \%)\end{array}$ & $\begin{array}{c}1 \\
(1.7 \%)\end{array}$ & $\begin{array}{c}0 \\
(0.0 \%)\end{array}$ & $\begin{array}{c}14 \\
(23.7 \%)\end{array}$ \\
\hline Total & $\begin{array}{c}7 \\
(11.9 \%)\end{array}$ & $\begin{array}{c}28 \\
(47.3 \%)\end{array}$ & $\begin{array}{c}15 \\
(25.5 \%)\end{array}$ & $\begin{array}{c}6 \\
(10.2 \%)\end{array}$ & $\begin{array}{c}3 \\
(5.1 \%)\end{array}$ & $\begin{array}{c}59 \\
(100 \%)\end{array}$ \\
\hline
\end{tabular}




\section{Empirical analysis and discussion of findings of cost accounting for BI\&A}

Evaluating our results in a three-stage process, we will highlight the most remarkable findings. In Section 4.1, we present the results of our survey by discussing the potential benefits in relation to the degree of implementation for the BI\&A cost accounting application areas. The findings will be discussed for each BI\&A stakeholder perspective. We will then combine these perspectives and analyze the potential benefits and the degree of implementation separately. The challenges for practical implementation and refinement of a BI\&A cost accounting are then described in Section 4.2. In the last section, we present a summary assessment of our findings.

\subsection{Evaluation of the potential benefits and degree of implementation}

To aid comprehensibility, the single application areas from Table 1 are abbreviated in the same order according to BI\&A development/operation from A1 to $\mathrm{A} 3, \mathrm{BI} \& \mathrm{~A}$ usage from $\mathrm{B} 1$ to $\mathrm{B} 4$, and $\mathrm{BI} \& \mathrm{~A}$ organization from $\mathrm{C} 1$ to $\mathrm{C} 6$. Furthermore, we select graphical diagrams to visualize differences and similarities. The relation between the potential benefits and degree of implementation could be interpreted as an indicator for desired "need for action" for the single application areas [8].

Figure 1 presents the results as mean ratings of how BI\&A users assessed the potential benefits and degree of implementation for each area of application. It is obvious that BI\&A users identify higher potential in those application areas where they benefit from directly or the opposite. At first, the high potential benefit in B2 (overall, partial project calculation), C1 (sensitization of customers for and economical usage of BI\&A) and C2 (increase of BI\&A understanding) means that we may assume that the users are willing to improve understanding in BI\&A organization to prevent inefficiencies. On the other hand, they see less potential in A3 of deleting uneconomical BI\&A applications. Maybe the risk of losing necessary applications is considered to high? Nevertheless, they asses other areas with high potential (A2: identification of cost drivers, B4: improvement to plan BI\&A resources, C4: allowing make-or-buy). From the low degree of implementation, we can conclude that from a BI\&A user perspective, the whole topic of BI\&A cost accounting in relation to the potential benefits creates both high potential and pronounced need for improvements.

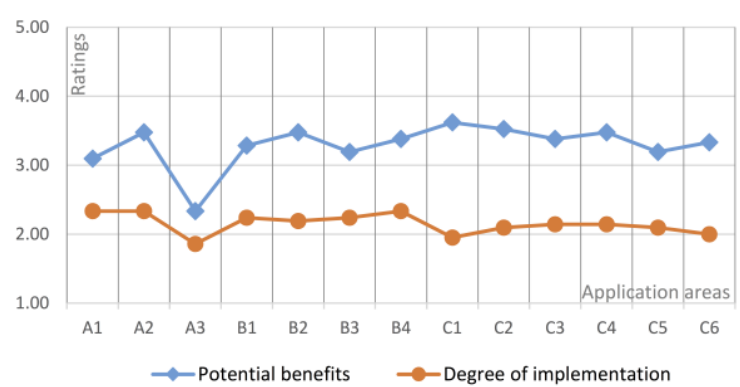

Figure 1. BI\&A users

Looking at the BI\&A developer perspective in Figure 2, we can begin by highlighting the lower potential benefit assessed for allowing outsourcing comparisons (C5). This may be explained by developers being unwilling to make themselves superfluous. Another obvious point is their low estimation of potential benefits for improvement in planning the users' BI\&A demands (B3). This can be explained by less involvement in this topic from an "end-user view". Furthermore, developers confirm most potential benefits, especially for the BI\&A usage category, e.g. in improving planning of BI\&A resource consumption (B4) or prioritizing order management by ROI (B1).

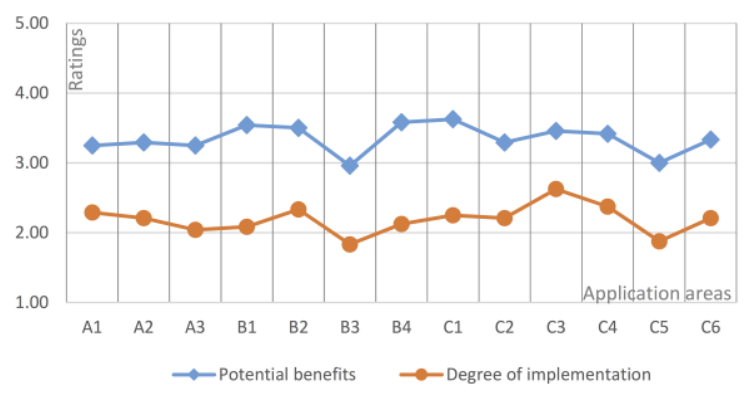

Figure 2. BI\&A developers

Another high potential is increasing awareness of BI\&A usage (C1) with BI\&A cost accounting. However, we can observe a homogenous course of both potential benefits and degrees of implementation with an assessment gap as shown in the BI\&A user perspective. This emphasizes the need for action in all application areas and gives further evidence for the need of a BI\&A cost accounting.

Not surprisingly, BI\&A mangers in Figure 3 see the most potential benefits in being able to justify their BI\&A organization to management (C3). Another remarkable area is the high potential in sensitizing BI\&A users to economical BI\&A usage (C1) and increasing BI\&A acceptance $(\mathrm{C} 2)$. In comparison to those high ratings, cancellation management (A3) has 
the lowest ratings. This contradicts with (C1) because, by deleting uneconomical BI\&A applications, resources would be freed up, especially in the BI\&A operations area. Nevertheless, BI\&A managers see high potential in prioritizing order management (B1), doing project calculations (B2), and executing service management with internal cost allocation (A1). Looking at the high degree of implementation assessed in these three areas B1, B2, A1 and C3, we are of the opinion that these areas represent the BI\&A mangers' daily business and that they are therefore most able to achieve results here. The most pressing need for action is situated in allowing make-or-buy decisions (C4), outsourcing comparisons (C5), and allowing cost benchmarks (C6) because it is here that the gap between assessed potential benefits and the degree of implementation is the highest. Once more, this is evidence for the high potential of $\mathrm{BI} \& \mathrm{~A}$ cost accounting to improve the current situation in BI\&A departments e.g. by creating cost transparency and allowing the invoicing of BI\&A costs to customers.

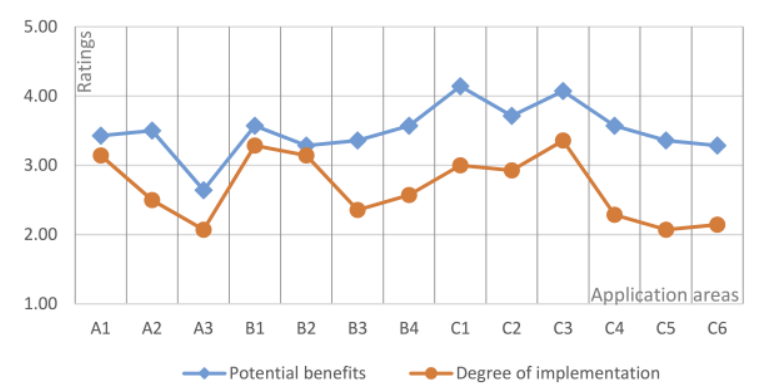

Figure 3. BI\&A managers

Looking at the potential benefits of all BI\&A stakeholders in Figure 4, we can confirm that there is a common understanding regarding the high potential benefits of cost accounting for BI\&A. Nevertheless, considering the low rates in $\mathrm{A} 3$ for users and managers and the high rates in $\mathrm{C} 1$ and $\mathrm{C} 3$ for managers, we can assert that there are divergent perceptions between the stakeholder types, clearly dependent on their role as users, developers, and managers. We can therefore assume a tendency for stakeholder types to have preferred application areas in which they assessed a higher or lower potential benefit. The two application areas with the highest assessed potential benefit are sensitization for customers for using BI\&A resources economically (C1) and justification to management (C3). Continuous cancellation management by cost evaluation (A3) is seen on average as the area with the lowest potential benefit.

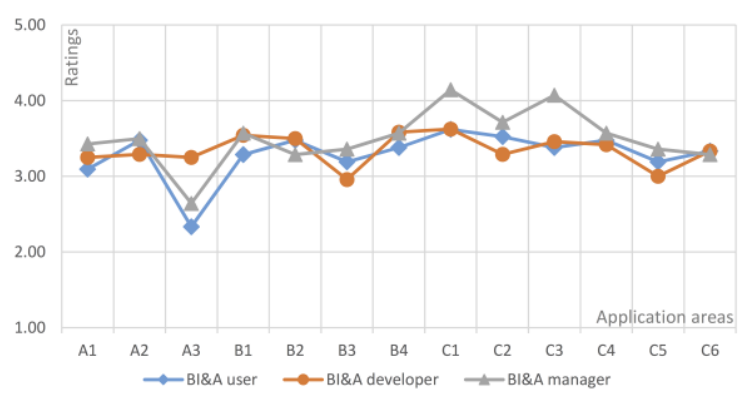

Figure 4. Potential Benefits of BI\&A stakeholders

Figure 5 shows that the degree of implementation in contrast to the potential benefit was, on average, assessed as lower. Justification to management (C3) and execution of service management with internal cost allocation (A1) are assessed with the highest degree of implementation. The lowest rate is ascribed by all stakeholder types to continuous cancellation management (A3). At the same time, there are higher differences in perception among the different stakeholders.

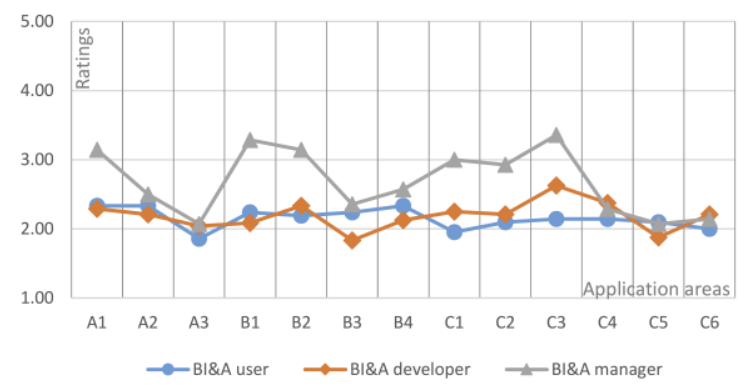

Figure 5. Degree of implementation of BI\&A stakeholders

Surprisingly, BI\&A managers show deep deviations in comparison to the other stakeholders $(\mathrm{A} 1, \mathrm{~B} 1, \mathrm{~B} 2, \mathrm{C} 1, \mathrm{C} 2, \mathrm{C} 3)$ regarding the degree of implementation. This is an especially important finding for managers because their assessments differ significantly from the other stakeholder types who are directly involved with development and operation of BI\&A systems and who can potentially estimate the degree of implementation more realistically. Consequently, managers should explicitly involve $\mathrm{BI} \& \mathrm{~A}$ users and BI\&A developers when it comes to taking decisions about BI\&A cost accounting. 


\subsection{Evaluation of challenges to practical implementation}

Companies are confronted by challenges when implementing or refining cost accounting for BI\&A. To get an insight into this topic, we use implementation challenges from [8] and adapt them for BI\&A cost accounting purposes. In the interests of comprehensibility, we abbreviate the implementation challenges listed in Table 2 from D1 to D8. In Figure 6, the assessments of all stakeholders are merged together in one diagram.

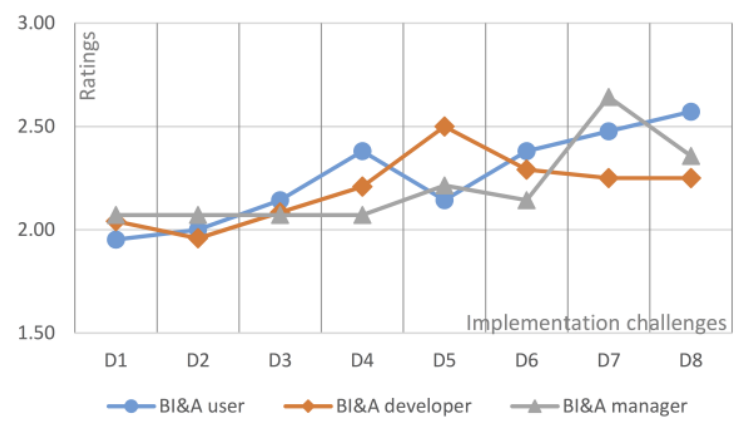

Figure 6. Implementation challenges of BI\&A stakeholders

Table 5 shows the corresponding data with mean value (MV), standard deviation (STD) and rank.

Table 5. Implementation challenges of BI\&A stakeholders

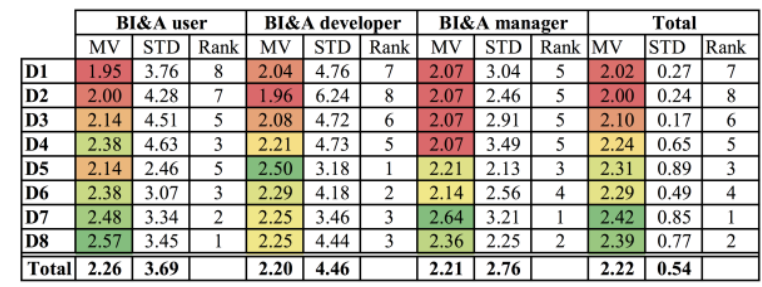

All three stakeholders assessed the effort of implementation challenges for BI\&A cost accounting overall as comparatively low, with a mean value of 2.22. This is true for all stakeholders, but especially of the BI\&A developers, who display their discrepancy with a standard deviation of 4.46 .

Representing a mean value of 2.42 with a standard deviation of 0.85 , the technical integration of cost accounting (D7) is the implementation challenge requiring the highest effort. The high standard deviation is produced due to the low assessment of 2.25 by the BI\&A developers. The availability of appropriate cost accounting approaches/ models for
BI\&A (D8) takes second place among the implementation challenges. At 2.00, all stakeholders assessed winning a project sponsor (D2) as requiring the lowest effort. However, beside these similarities, there are some notable differences in the assessment of implementation challenges. The availability of appropriate cost accounting tools (D5) represents the highest manageable implementation challenge for the BI\&A developers. From a BI\&A user perspective, the availability of development resources (D4) and the organizational establishment of cost accounting (D6) are difficult implementation challenges. In summary, an approach or model (D8, D6) and technical assistance (D7, D5) in implementing BI\&A cost accounting dominate this evaluation. At the same time, organizational motivation (D1, D3) and realization (D2, D4) are evaluated as much lower.

\subsection{Discussion of the findings}

The evaluation differentiated by stakeholder-types clearly shows significant deviations in the assessment of the status quo and the implementation challenges for BI\&A cost accounting between those groups. This allows us to confirm the influence of stakeholder perspectives on the evaluation of IS as stipulated in Section 2.2.

With regard to the single stakeholder perspectives, we assume that stakeholders assign higher or lower benefits to application areas according to the extent to which they benefit from them. This can be clearly seen for BI\&A users in respect of cancellation management. Presumably, users are trying to reduce the risk of losing their BI\&A applications. On the other hand, BI\&A users are motivated to support a cost accounting initiative. BI\&A developers assessed improved evaluation of outsourcing possibilities as well as providing BI\&A users with an individual service catalog as less important. We think this low assessment can be explained by lower involvement in those application areas by developers. Accordingly, BI\&A managers assessed justification to management as their most important area; this is, after all, one of their occupations. Another point we want to emphasize from the BI\&A managers' perspective is the highest total rating of the potential benefits and the degree of implementation. This could be explained by the way BI\&A cost accounting is classified as a management tool; BI\&A users and developers have nearly the same total rating. However, when compared to BI\&A managers, a higher need for action for users and developers across all application areas dominates their assessments.

This leads us to the issue of distortions due to perception. We assume that BI\&A users and 
developers are closer to the action and therefore in a position to assess BI\&A cost accounting implementation more realistically than BI\&A mangers. Especially when looking at the degree of implementation, deviations are visible due to varying degrees of involvement in the application areas. The different perceptions might cause suboptimal results when it comes to designing or implementing BI\&A cost accounting. The rather low level of conviction among BI\&A users and developers we found could lead to inaccurate BI\&A cost accounting because they may have to estimate efforts for BI\&A projects which are forwarded to customers. Furthermore, the risk of accepting by these two perspectives after implementation increases when there is no common understanding about the use and benefits of BI\&A cost accounting and may further negatively affect companies' BI\&A systems. Therefore, BI\&A managers should explicitly involve BI\&A users and developers in the process with regard to development, implementation or refinement of BI\&A cost accounting initiatives.

These differences in perception are also visible in the assessment of implementation challenges. However, there is a common understanding about the importance of a suitable approach and technical assistance when implementing a BI\&A cost accounting.

One major implementation challenge we identify in this study is the gap in BI\&A cost accounting approaches or models. To improve this situation, we recommend reading further research results, for example on introducing BI\&A service-oriented cost accounting in [14].

Through the findings of our survey, we conclude the following:

- divergent perceptions among users, developers and managers which can lead to less acceptance and less success when introducing BI\&A cost accounting,

- users want to protect their BI\&A applications, developers try not to be superfluous whereas managers need a cost accounting system most for justification,

- the chance of selling a BI\&A cost accounting system in enterprises increases when concentrating on managers because of their high belief in the use and utility of a cost accounting function,

- $\quad$ higher acceptance of BI\&A cost accounting and project success can be achieved when considering the defined and prioritized needs for action and implementation challenges.
From our analysis, we can conclude that there is high potential for establishing BI\&A cost accounting and that companies in our population have a pronounced need for action of which they are, at the very least, well aware.

\section{Limitations and further work}

There are limitations to this paper: primarily, interpreting the results of the analysis of the differences in perception among stakeholders regarding the development or refinement of BI\&A cost accounting. On the one hand, there are restrictions to the underlying research concept; on the other hand, there are limitations relating to the number of cases in the sample collection. The available data set is not representative and is therefore not suitable for generalizing our findings. To achieve this, more studies are needed.

With the data set available, further research is conceivable by analyzing more questions. It may be possible to take the amount of BI\&A users, the heterogeneity of the BI\&A system landscape, or the amount of employees working in a BI\&A department into account. From so doing, we expect a deeper understanding about cost accounting usage. Our future aim is to implement appropriate BI\&A cost accounting approaches to evaluate how stakeholder perceptions are affected.

A useful contribution could be expected when stakeholders are made to consider the most promising application areas for them when implementing or improving their BI\&A cost accounting and to take the resulting order of implementation challenges into account.

\section{References}

[1] Baars, H., C. Felden, P. Gluchowski, A. Hilbert, H.-G. Kemper, and S. Olbrich, "Shaping the Next Incarnation of Business Intelligence", Business \& Information Systems Engineering, 6(1), 2014, pp. 11-16.

[2] Baars, H. and H.-G. Kemper, "Business intelligence in the cloud?", PACIS 2010 Proceedings, 2010.

[3] Berghout, E. and D. Remenyi, "The Eleven Years of the European Conference on IT Evaluation: Retrospectives and Perspectives for Possible Future Research", Electronic Journal of Information Systems Evaluation, 8(2), 2005, pp. 81-98.

[4] Brandl, R., M. Bichler, and M. Strobel, "Cost accounting for shared IT infrastructures", Wirtschaftsinformatik, 49(2), 2007, pp. 83-94. 
[5] Chen, H., R.H.L. Chiang, and V.C. Storey, "Business Intelligence and Analytics: From Big Data to Big Impact", MIS quarterly, 36(4), 2012, pp. 1165-1188.

[6] Delone, W.H. and E.R. McLean, "The DeLone and McLean Model of Information Systems Success: A TenYear Update", Journal of Management Information Systems, 19(4), 2003, pp. 9-30.

[7] Dinter, B., "The Maturing of a Business Intelligence Maturity Model", in Proceedings of the American Conference on Information Systems (AMCIS'2011). 2011: Detroit, Michigan, USA.

[8] Dinter, B., P. Gluchowski, and C. Schieder, "A Stakeholder Lens on Metadata Management in Business Intelligence and Big Data - Results of an Empirical Investigation Rico", in 21st Americas Conference on Information Systems, AMCIS 2015, Puerto Rico. 2015.

[9] Dinter, B., C. Schieder, and P. Gluchowski, "Towards a Life Cycle Oriented Business Intelligence Success Model Competitiveness. 17th Americas Conference on Information Systems, AMCIS 2011", in A Renaissance of Information Technology for Sustainability and Global Competitiveness. 17th Americas Conference on Information Systems, AMCIS 2011, Detroit, Michigan, USA, V. Sambamurthy and M. Tanniru, Editors. 2011.

[10] Epple, J., S. Bischoff, and S. Aier, "Management Objectives and Design Principles for the Cost Allocation of Business Intelligence", in PACIS. 2015.

[11] Gansor, T. and A. Totok, Von der Strategie zum Business Intelligence Competency Center (BICC): Konzeption, Betrieb, Praxis, 2nd edn., dpunkt.verlag; TDWI Europe, Heidelberg, 2015.

[12] Gibson, M., D. Arnott, and I. Jagielska, "Evaluating the Intangible Benefits of Business Intelligence: Review \& Research Agenda", Decision Support in an Uncertain and Complex World: The IFIP TC8/WG8.3 International Conference 2004, 2004, pp. 295-305.

[13] Grover, V., S.R. Jeong, and A.H. Segars, "Information systems effectiveness: The construct space and patters of application", Information \& Management, 31(4), 1996, pp. 177-191.

[14] Grytz, R. and A. Krohn-Grimberghe, "Serviceoriented Cost Allocation for Business Intelligence and Analytics: Who pays for BI\&A?", in Proceedings of the 50th Hawaii International Conference on System Sciences. 2017.

[15] Hagerty, J., R.L. Sallam, and J. Richardson, "Magic quadrant for business intelligence platforms", 2012.

[16] Hamel, F., T.P. Herz, F. Uebernickel, and W. Brenner, "State of the art: Managing costs and performance of Information Technology", AMCIS 2010 Proceedings(Paper 516), 2010

[17] Horakh, T.A., H. Baars, and H.-G. Kemper, "Mastering Business Intelligence Complexity-A Service-
Based Approach as a Prerequisite for BI Governance", AMCIS 2008 Proceedings, 2008, p. 333

[18] Kaisler, S., F. Armour, and A. Espinosa, "Introduction to Big Data and Analytics: Concepts, Methods, Techniques, and Application Minitrack", in Proceedings of the 50th Hawaii International Conference on System Sciences. 2017.

[19] Kaisler, S., F. Armour, J.A. Espinosa, and W. Money, "Big Data: Issues and Challenges Moving Forward", in 2013 46th Hawaii International Conference on System Sciences, 2013 46th Hawaii International Conference on System Sciences (HICSS), Wailea, HI, USA, 07.01.2013 10.01.2013. 2013. IEEE.

[20] Kaplan, R.S. and R. Cooper, Cost \& effect: Using integrated cost systems to drive profitability and performance, 9th edn., Harvard Business School Press, Boston, Mass., 2005.

[21] Klesse, M., "Methode zur Gestaltung einer Leistungsverrechnung für DWH Competence Center", in Active Enterprise Intelligence ${ }^{\mathrm{TM}}, \mathrm{J}$. Töpfer and R. Winter, Editors. 2008. Springer Berlin Heidelberg.

[22] Lönnqvist, A. and V. Pirttimäki, "The Measurement of Business Intelligence", Information Systems Management, 23(1), 2006, pp. 32-40.

[23] Miller, G.J., D. Bräutigam, and S.V. Gerlach, Business intelligence competency centers: A team approach to maximizing competitive advantage, John Wiley \& Sons, Hoboken, N.J, 2006.

[24] Moss, L.T. and S. Atre, Business intelligence roadmap: The complete project lifecycle for decisionsupport applications, Addison-Wesley, Boston, MA, 2003.

[25] Negash, S., "Business intelligence", The Communications of the Association for Information Systems, 13(1), 2004, p. 54.

[26] Schieder, C. and P. Gluchowski, "Towards a consolidated research model for understanding business intelligence success", in ECIS. 2011.

[27] Seddon, P.B., D. Constantinidis, T. Tamm, and H. Dod, "How does business analytics contribute to business value?", Information Systems Journal, 27(3), 2017, pp. 237-269.

[28] Seddon, P.B., S. Staples, R. Patnayakuni, and M. Bowtell, "Dimensions of Information Systems Success", Commun. AIS, 2(3es), 1999.

[29] van Maanen, H. and E. Berghout, "Cost management of IT beyond cost of ownership models: a state of the art overview of the Dutch financial services industry", Evaluation and Program Planning, 25(2), 2002, pp. 167173.

[30] Wu, J., "Calculating the ROI for Business Intelligence Projects", 2000 (http://www.informationmanagement.com/news/2487-1.html, 14-06-2017). 